\title{
The Effect of a Proximal and Distal Tibiofibular Joint Manipulation on Dorsiflexion and Balance in Individuals with a History of Lateral Ankle Sprain
}

\author{
Yun-Won Chae' ${ }^{1}$ Ji-Won Park², Ki-Seok Nam ${ }^{3}$ \\ 'Department of Physical Therapy, Gwangju Health College, Gwangju; ${ }^{2}$ Department of Physical Therapy, College of Medical Health, Catholic \\ University of Daegu, Gyeongsan; ${ }^{3}$ Department of Physical Therapy, Yeungnam University College, Daegu, Korea
}

Purpose: This study aimed to evaluate the changes in dorsiflexion and balance following proximal and distal tibiofibular joint manipulation in individuals with a history of lateral ankle sprain (LAS).

Methods: Fifteen participants with a history of unilateral LAS, exhibiting a restriction in ankle dorsiflexion were included in this study. LAS ankle received a manipulation to the proximal and distal tibiofibular joint, while the opposite control ankle received no manipulation intervention. The outcome measures included ankle dorsiflexion and balance. Ankle dorsiflexion was measured using weight-bearing lunge test. Static and dynamic balances were measured using the overall, anterioposterior, and mediolateral balance index via the biodex balance system. Measurements were obtained prior to and following manipulation.

Results: This study showed that ankle dorsiflexion and dynamic balance were improved following the manipulation compared to those prior to the manipulation $(p<0.05)$. There was no significant change in static balance $(p>0.05)$.

Conclusion: The joint manipulation technique applied to the ankle of those with a history of LAS appears to improve ankle dorsiflexion and dynamic balance. This suggest that a manipulation to the proximal and distal tibiofibular joint could be provided as preliminary data regarding the prophylactic effects of recurrent LAS.

Keywords: Lateral ankle sprain, Manipulation, Dorsiflexion, Balance

\section{서 론}

발목은 급성 근육뼈대계 손상이 가장 빈도 높게 발생하는 부위들 중 하나이며, 발목 손상의 약 $75 \%$ 는 염좌의 형태로 나타난다. ${ }^{1}$ 발목염좌 의 $96 \%$ 는 가쪽발목염좌(lateral ankle sprain, LAS)가 차지하고 있다. ${ }^{2}$ $\mathrm{LAS}$ 는 3 등급 체계로 분류되는데 이 중 I 등급이 약 $71 \%$ 가 된다. ${ }^{3}$ 따 라서 LAS 환자의 대부분은 심각한 증상과 기능장애를 보이지 않기 때문에 병원을 찾지 않고 자가관리하는 경우가 약 $55 \%$ 나 되며, ${ }^{4}$ 병원 을 내원한 경우에도 전통적인 물리치료로 치료되는 경우가 대부분 이다.

LAS에 대한 전통적인 물리치료에서는 RICE (안정, 냉, 압박, 거상) 기법과 초기 가동성을 위한 기법이 처방된다. ${ }^{5}$ 처음 발목염좌를 당한 사람들의 경우, 전통적인 물리치료를 통해 2주 이내에 일반적인 통증 의 감소 및 운동과 기능의 개선을 보였으나, 3 년의 추적조사에서 환자

Received Mar 16, 2017 Revised Apr 30, 2017

Accepted Apr 30, 2017

Corresponding author Ki-Seok Nam

E-mail seokah@hanmail.net
의 약 $34 \%$ 가 재손상이 발생하였다고 보고되고 있다. ${ }^{6}$ 이런 재손상이 발생하는 이유로는 전통적인 물리치료를 통해 발등쪽굽힘이 완전히 회복되지 못한 것과 균형 예방 프로그램을 실시하지 않음으로 발생 하는 균형의 문제가 원인이 된다. ${ }^{7}$ LAS의 높은 재발률과 만성발목불 안정성(chronic ankle instability, CAI)으로의 진행률을 고려한다면, 적 절한 치료와 재발을 방지하기 위한 고려가 필요한 실정이다.

LAS 이후 발생한 발등쪽굽힘의 감소와 관절 가동성의 제한은 계 단 내려오기나 달리기와 같은 기능적 활동 동안 관절의 역학을 변경 시킬 수 있다. ${ }^{8}$ 이러한 상황은 관절로부터 들어오는 들신경 신호를 변 경시켜 운동신경세포집단(motor neuron pool) 흥분성의 감소를 초래 하게 되며, 이에 대한 반사적 반응으로 긴종아리근과 가자미근은 발 목염좌 후 억제되게 된다. ${ }^{9}$ 기능적 활동을 하는 동안, 발목을 안정시 키는 데 필요한 근육이 억제되어 발생되는 균형의 문제와 발등쪽굽 힘의 감소는 전반적인 발목의 기능을 감소시켜 발목염좌의 재발을
Copylight (C)2017 The Korea Society of Physical Therapy

This is an Open Access article distribute under the terms of the Creative Commons Attribution Non-commercial License (Http:// creativecommons.org/license/by-nc/4.o.) which permits unrestricted non-commercial use, distribution, and reproduction in any medium, provided the original work is properly cited. 
높이는 중요한 요소가 된다.10

발목의 발바닥쪽굽힘근육들에 대한 정적신장이 발등쪽굽힘을 증 진시키는 데 일반적으로 사용되지만, LAS 이후 발생한 발등쪽굽힘 제한의 근본적인 원인은 발바닥쪽굽힘근육들의 타이트니스(tightness)가 아니라 비수축성조직에 의해 유발된 관절 운동의 제한이다."1 LAS 이후 발등쪽굽힘의 가동성은 대부분 회복되지만 비수축성조직 의 제한이 여전히 존재하기 때문에, 목말뼈나 종아리뼈의 위치적 정 렬 변화에 의한 관절운동형상학의 변경에 의해 발등쪽굽힘의 끝범 위 제한은 계속 남게 된다. 이러한 비수축성조직에 의한 관절 운동의 제한은 관절의 가동기법(mobilization)이나 도수교정(manipulation)과 같은 도수치료를 통해 회복되어야 한다.

LAS에 대한 도수치료는 발등쪽굽힘의 증진과 균형을 개선시키기 위해 이용되고 있다. Marrón-Gómez 등른 CAI 환자에 대한 목말종 아리관절의 가동기법과 도수교정이 발등쪽굽힘을 증가시켰다고 보 고 하였다. Vicenzino 등'은 재발성발목염좌에 대한 목말종아리관절 의 가동기법이 발등쪽굽힘의 양을 증가시켰다고 보고하였다. CruzDíaz 등 ${ }^{14}$, Hoch 등 ${ }^{15}$, 그리고 Hoch와 McKeon ${ }^{16}$ 은 CAI 환자에 대한 목 말종아리관절의 가동기법이 발등쪽굽힘과 균형의 증진을 가져왔다 고 보고하였다. Fisher 등근 목말종아리관절의 도수교정이 겉질척수 (corticospinal) 흥분성을 증가시켜 근육 동원을 개선하였다고 보고하 였다. 이러한 선행 연구들은 주로 목말종아리관절에 대해 연구하였 으며, 대상자 또한 대부분 CAI 환자에 대해 이루어졌다. 발등쪽굽힘 과 균형의 개선이 치료적 관점보다는 예방적 관점에서 본다면, LAS의 병력이 있는 사람들을 대상으로 한 연구도 필요한 실정이다.

관절운동형상학적 관점에서, 발목이 발등쪽굽힘을 수행할 때 목 말뼈는 뒤쪽으로 미끄러져야 한다. 목말뼈의 도르래면은 앞쪽이 더 넓기 때문에, 발등쪽굽힘의 끝범위에 도달하기 위해서는 목말뼈와 접촉하게 되는 먼쪽종아리뼈의 뒤쪽 미끄러짐과 몸쪽종아리뼈의 앞쪽 미끄러짐이 필요하게 된다.18 정상 보행에서는 적어도 10 도의 발 등쪽굽힘이 요구되지만 달리기, 계단 내려오기, 또는 쪼그려 앉기와 같은 기능적 동작들은 더 많은 발등쪽굽힘이 필요하게 된다. ${ }^{19}$ 이러 한 상황으로 볼 때, LAS의 병력이 있는 사람들이 발등쪽굽힘의 끝범 위가 완전히 회복되지 않은 상황에서 기능적 활동을 한다면 재발의 위험은 증가할 것이며, 몸쪽과 먼쪽정강종아리관절의 완전한 관절 운동의 회복은 필요할 것이다.

따라서, 본 연구는 LAS의 병력을 갖고 있으면서 발등쪽굽힘에 제 한이 있는 대상자를 대상으로 몸쪽과 먼쪽정강종아리관절에 대해 도수교정을 적용하여 발등쪽굽힘과 균형에 대해 미치는 영향을 연 구하고자 한다.

\section{연구 방법}

\section{1. 연구대상}

본 연구에서는 몸쪽과 먼쪽정강종아리관절에 대한 도수교정이 발 등쪽굽힘과 균형에 미치는 영향을 알아보기 위한 대상자 선정을 위 해 LAS의 병력을 갖고 있는 사람들을 대상으로 설문지와 측정을 통 해 선정하였다. 설문지를 통한 일차 대상자 선정의 조건으로는 1)지난 2년 내에 LAS의 병력을 갖고 있는 자, 2)병력이 있었던지 6개월 이상 인 자, 3)한쪽에만 병력이 있으며 반대쪽에는 병력이 없는 자, 4) 쪼그 려 앉기의 마지막에 제한이 있는 자로 하였다. 대상자 선정의 배제 조 건으로는 1) LAS에 의해 수술이나 석고 고정을 했던 자, 2)현재 염좌 의 증상을 갖고 있는 자,3) $\mathrm{CAI}$ 를 갖고 있는 자, 4) 발목에 질환을 갖고 있는 자, 5)이전에 허리, 엉덩관절, 또는 무릎관절에 대해 수술을 받았 던 자로 하였다.

위의 조건을 충족한 62 명을 대상으로 체중부하 런지검사를 이용한 발목의 발등쪽굽힘을 측정하여 환측과 건측의 차이가 $2 \mathrm{~cm}$ 이상인 15 명을 최종적으로 선정하였다. 대상자 15 명은 남성 8 명과 여성 7 명이 며, 평균 키는 $168.54 \pm 8.97 \mathrm{~cm}$ 이고 평균 몸무게는 $60.37 \pm 13.52 \mathrm{~kg}$ 이며 평균 나이는 $22.12 \pm 2.42$ 세이다. 실험 전 모든 대상자들에게 실험에 대 해 충분히 설명한 후, 대상자들의 자발적 동의를 얻어 진행하였다.

\section{2. 실험방법}

\section{1) 측정방법}

(1) 발등쪽굽힘

본 연구에서 측정한 발목의 발등쪽굽힘의 양은 체중부하 런지검사 (weight-bearing lunge test)로 측정하였다. 이 검사를 하기 위해서 검사 쪽 다리의 둘째발가락, 발꿈치의 중심, 그리고 무릎의 중심이 벽면에 대해 수직을 이룬 상태로 서 있고, 반대쪽 다리는 검사쪽 다리의 뒤 쪽에 위치시켜 안정성을 유지하게 한다. 이 상태에서 둘째발가락이 벽면에서 $2 \mathrm{~cm}$ 떨어진 위치에서 무릎이 벽면에 닿게 하여 검사를 시 작한다. 대상자가 무릎을 벽면에 접촉하고 있는 상태에서 발을 천천 히 뒤쪽으로 움직이게 하여 발목의 발등쪽굽힘이 최대로 이루어지 도록 한다. 발꿈치가 떨어지거나 무릎이 벽면과의 접촉을 유지할 수 없을 때 둘째발가락과 벽면 사이의 거리를 측정하여 최대 발등쪽굽 힘의 양을 측정한다. 결과값은 3 회를 실시한 후 평균값을 이용했다. 이 검사법은 검사자내 급내상관계수가 0.97 과 0.98 사이의 범위이며 평균표준오차가 $0.5-0.6 \mathrm{~cm}$ 를 보여 높은 검사자 내 신뢰도를 갖고 있 으며, 검사자 간 급내상관계수가 0.99 이며 평균표준오차가 $0.4 \mathrm{~cm}$ 를 보여 높은 검사자 간 신뢰도를 가지고 있다. ${ }^{20}$ 
(2) 균형

균형을 측정하기 위해 biodex balance system (Biodex Inc, USA)을 사용 하여 전체균형지수(overall stability index, OSI), 앞뒤쪽균형지수(anterioposterior stability index, APSI), 안가쪽균형지수(mediolateral stability index, MLSI)를 측정하였다. 정적인 균형은 발판이 고정되어 있는 상 태에서 모니터에 나온 동심원의 중심에 스스로 자신의 압력중심 (center of pressure)을 위치시킨 후 검사를 시작하였다. 20초 동안 2회 측정하였으며, 중간에 10 초의 휴식을 가졌다. 동적인 균형을 측정할 때에는 발판이 고정되어 있지 않으며, 발판의 불안정성은 1-12단계까 지로 다양하게 조절할 수 있도록 되어 있다. 12 단계가 가장 안정적이 고 1단계가 가장 불안하다. 본 실험에서는 5 단계를 이용해 실시하였 다. 발판이 5 단계로 설정된 상태에서 모니터에 나온 동심원의 중심에 스스로 자신의 압력중심을 위치시킨 후 검사를 시작하였다. 20 초 동 안 2 회 측정하였으며 중간에 10 초의 휴식을 가졌다. 측정값은 OSI, APSI, MLSI로 기록하였다.

\section{2) 도수교정}

대상자는 치료대에 바로 누운자세를 취한다. LAS 병력이 있는 쪽 몸 쪽정강종아리관절의 도수교정을 위해 치료사의 둘째손가락을 대상 자 무릎 뒤쪽의 약간 아래쪽으로 넣어 종아리뼈머리의 뒤쪽면에 접 촉한다. 이때 종아리뼈머리에 견고하게 접촉하기 위해 손허리손가락 관절이 닿을 때까지 연부조직을 가쪽으로 당긴다. 반대쪽 손은 대상 자의 발목 앞쪽을 잡아 아래다리가 가쪽돌림되게 한다. 대상자의 무 릎은 제한점이 느껴지는 끝지점까지 굽힘시키고, 제한점이 느껴지는 지점에서 빠른 속도-낮은 진폭의 도수교정을 적용한다. 이때 힘의 방 향은 정강뼈가 대상자의 같은쪽 엉덩이쪽으로 향하도록 하여 종아리 뼈머리가 앞쪽으로 병진운동하게 한다. 이러한 동작을 2 회 실시한다.

LAS 병력이 있는 쪽 먼쪽정강종아리관절의 도수교정을 위해 한 손으로 먼쪽정강뼈를 잡고 다른 손의 엄지두덩과 손가락으로 먼쪽 종아리뼈를 잡는다. 먼쪽종아리뼈를 제한점이 느껴지는 끝지점까지

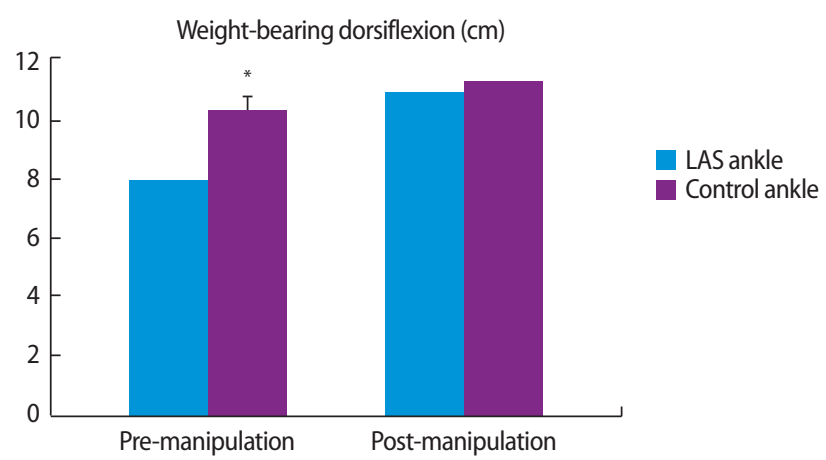

Figure 1. The difference in weight-bearing dorsiflexion measurements (cm) on LAS and control ankle before and after manipulation ( $\left.{ }^{*} p<0.05\right)$.
뒤쪽으로 병진운동을 시킨다. 제한점이 느껴지는 지점에서 빠른 속 도-낮은 진폭의 도수교정을 뒤쪽과 약간 위쪽으로 적용한다. 이러한 동작을 2 회 실시한다.

몸쪽과 먼쪽정강종아리관절의 도수교정이 LAS 병력이 있는 쪽 발 목의 발등쪽굽힘에 효과가 있는지 비교하기 위해, LAS 병력이 없는 쪽 발목의 발등쪽굽힘을 대조군으로 설정하였다. 대조군으로 설정된 반대쪽 몸쪽과 먼쪽정강종아리관절은 LAS 병력이 있는 쪽 몸쪽과 먼쪽정강종아리관절의 도수교정에 소요된 비슷한 시간인 1-2분 동 안 치료대에 눕게 하고, 치료사는 대상자와 신체적 접촉을 배제하였 다.

도수교정은 일주일에 3회를 실시하고 2주간 총 6회의 치료를 적용 하였다.

\section{3) 통계처리}

통계처리는 SPSS 19.0 ver. Window를 사용하였다. 도수교정의 적용 전 과 적용 후에 있어 LAS 병력이 있는 쪽 발목과 없는 쪽 발목의 발등쪽 굽힘의 차이를 알아보기 위해 independent t-test를 실시하였으며, 도 수교정에 의한 발등쪽굽힘과 정적 및 동적인 상태하에서의 OSI, APSI, MLSI의 차이를 알아보기 위해 paired t-test를 사용하여 분석하 였다. 유의수준 $\alpha=0.05$ 로 하였다.

\section{결 과}

\section{1. 체중부하 런지검사를 이용한 발등쪽굽힘의 차이}

도수교정을 적용하기 전에 측정한 LAS 병력이 있는 발목과 병력이 없 는 대조군 발목의 발등쪽굽힘의 차이는 평균 $2.98 \pm 0.71$ 로 유의한 차 이가 있었으나 $(\mathrm{p}<0.05)$, 도수교정을 적용한 후에는 유의한 차이가 없 었다(Figure 1). LAS 병력이 있는 쪽의 몸쪽과 먼쪽정강종아리관절에 대한 도수교정은 적용하기 전과 적용한 후의 발등쪽굽힘에 있어 유 의한 차이가 있었으나 $(\mathrm{p}<0.05)$, 도수교정을 적용하지 않은 LAS 병력 이 없는 대조군 발목에서는 유의한 차이가 없었다(Table 1). 몸쪽과 먼 쪽정강종아리관절에 대한 도수교정은 LAS 병력이 있는 발목의 발등 쪽굽힘에 영향을 미치는 것으로 나타났다.

Table 1. The difference in weight-bearing dorsiflexion measurements (cm) before and after manipulation on LAS and control ankle

\begin{tabular}{lccc}
\hline & Pre-manipulation & Post-manipulation & p-value \\
\hline LAS ankle & $7.94 \pm 2.89$ & $10.34 \pm 2.39$ & $0.03^{*}$ \\
Control ankle & $10.92 \pm 2.82$ & $11.23 \pm 2.52$ & 0.61 \\
\hline
\end{tabular}

Values are presented as mean \pm standard deviation. ${ }^{*} \mathrm{p}<0.05$. 
Table 2. The differences in overall stability index (OSI), anterioposterior stability index (APSI), and mediolateral stability index (MLSI) of static and dynamic stability index before and after manipulation

\begin{tabular}{llccc}
\hline & & Pre-manipulation & Post-manipulation & p-value \\
\hline Static & OSI & $0.48 \pm 0.15$ & $0.43 \pm 0.17$ & 0.51 \\
& APSI & $0.35 \pm 0.12$ & $0.33 \pm 0.15$ & 0.61 \\
& MLSI & $0.24 \pm 0.09$ & $0.17 \pm 0.08$ & 0.10 \\
Dynamic & OSI & $1.62 \pm 0.22$ & $1.18 \pm 0.16$ & $0.00^{*}$ \\
& APSI & $1.24 \pm 0.31$ & $0.93 \pm 0.29$ & $0.01^{*}$ \\
& MLSI & $0.96 \pm 0.27$ & $0.69 \pm 0.17$ & $0.01^{*}$ \\
\hline
\end{tabular}

Values are presented as mean \pm standard deviation ${ }^{*} \mathrm{p}<0.05$.

\section{2. 도수교정이 균형에 미치는 영향}

정적인 균형을 측정한 결과, OSI, APSI, MLSI는 도수교정을 적용하기 전 과 후의 변화는 없었다. 동적인 균형을 측정한 결과, OSI, APSI, MLSI는 도수교정을 적용하기 전과 후에 있어 유의한 차이를 보였다 $(\mathrm{p}<0.05)$. LAS 병력이 있는 대상자에 대한 몸쪽과 먼쪽정강종아리관절의 도수교 정이 동적인 균형에 영향을 미치는 것으로 나타났다(Table 2).

\section{고 찰}

몸쪽과 먼쪽정강종아리관절에 도수교정을 적용한 본 연구의 결과는 LAS 병력을 가진 대상자들의 발등쪽굽힘과 동적인 균형에 유의한 개선을 보였다. 도수교정을 적용하지 않은 반대쪽 발목의 발등쪽굽 힘은 변화가 없는 것에 비해, 2주간 도수교정을 적용한 LAS 병력이 있 는 발목의 발등쪽굽힘은 유의하게 증가하였다. OSI, APSI, MLSI로 측 정된 균형에 있어, 도수교정은 정적인 균형에는 별 영향을 미치지 않 았지만 동적인 균형에서는 유의한 개선을 보였다.

발등쪽굽힘을 측정하기 위해 체중부하 런지검사를 이용하였다. 이 검사법은 발목에서의 최대 발등쪽굽힘을 요구하기 때문에, 반복 적인 검사는 발등쪽굽힘의 증가 원인이 될 수 있다. Beazell 등 21 은 도 수교정을 적용하지 않은 대조군에서도 체중부하 런지검사의 반복적 인 측정에 의해 발등쪽굽힘이 증가하였기 때문에, 몸쪽정강종아리 관절 또는 먼쪽정강종아리관절 각각에 도수교정을 적용 후 얻은 발 등쪽굽힘의 증가는 치료의 효과로 보기 어렵다고 하였다. 따라서 본 연구에서는 반복적인 측정을 통해 발등쪽굽힘에 영향을 미칠 수 있 는 것을 최소화하기 위해 도수교정을 적용하기 전과 후 만을 비교하 였다. 도수교정을 적용하지 않은 반대쪽 발목에서의 발등쪽굽힘이 변화가 없는 것으로 보아, LAS 병력이 있는 발목에서의 발등쪽굽힘 의 증가는 도수교정의 효과로 보인다.

Fryer 등 22 의 연구에 따르면, 정상적인 목말종아리관절에 대한 도수 교정은 발등쪽굽힘에 영향을 미치지 않는다고 하였다. 그러나 CAI
환자들은 발등쪽굽힘의 제한을 가지고 있으며, 가동기법이나 도수교 정에 의해 발등쪽굽힘이 개선된다고 보고하고 있다. ${ }^{14-16,23}$ 이러한 연 구들을 통해 $\mathrm{CAI}$ 환자들이 정상인에 비해 발등쪽굽힘의 제한을 갖 고 있다는 것을 알 수 있다. CAI 환자에서 나타나는 발등쪽굽힘의 감 소는 염좌의 재발에 의해 목말종아리관절의 느슨함이 증가하게 되 고, 이로 인해 목말뼈가 앞쪽에 놓이는 위치 결함을 유발하여 목말종 아리관절에서의 관절운동형상학을 방해하는 것으로 보고되고 있 다. ${ }^{12}$ 그러나, $\mathrm{CAI}$ 환자는 목말종아리관절에 의한 발등쪽굽힘의 감소 를 결과적으로 갖고는 있지만, $\mathrm{CAI}$ 의 원인이 되는 발등쪽굽힘의 감 소 원인이 목말종아리관절인지 아니면 다른 관절에 의한 것인지는 명확하지 않다. Andersen 등 24 의 연구에 따르면, 현재 증상을 갖고 있 지 않으며 재발된 적이 없는 LAS 병력의 대상자에 대해 목말종아리 관절에 대한 도수교정을 적용한 결과 발등쪽굽힘의 증가는 없다고 보고하였다. 이러한 결과들로 볼 때 LAS의 재발의 원인이 되는 발등 쪽굽힘의 감소 원인의 하나로 정강종아리관절에서의 관절운동형상 학적 제한도 요인이 될 수 있다고 가설을 세울 수 있다.

LAS가 있는 쪽 먼쪽정강종아리관절은 반대쪽 그리고 LAS가 없는 같은 쪽 대조군에 비해 먼쪽종아리뼈가 앞쪽에 놓이는 위치 결함을 가지고 있다고 보고하였다. ${ }^{25,26}$ Hubbard와 Hertel ${ }^{25}$ 은 이러한 먼쪽종 아리뼈의 위치 결함이 LAS가 있는 사람의 $82 \%$ 에서 나타났다고 보고 하여, 모든 LAS 환자에게서 나타나는 것은 아니라고 하였다. 또한 Ka$\operatorname{vanagh}^{27}$ 는 먼쪽종아리뼈의 앞쪽 이동이 발등쪽굽힘의 제한이 있는 LAS쪽 먼쪽정강종아리관절에서 나타난다고 하였다. 이런 먼쪽종아 리뼈의 위치 결함은 발등쪽굽힘의 끝범위에 영향을 미치기 때문에 일반적인 보행에서는 문제가 되지 않을 수 있지만, 달리기, 계단 내려 오기, 쪼그려 앉기와 같은 발등쪽굽힘의 끝범위가 요구되는 기능적 활동들에서는 LAS의 재발 원인이 될 것이다.

관절의 가동기법 또는 도수교정은 관절주머니나 주변 인대들과 같 은 비수축성조직의 제한이 있어 관절의 저가동성을 유발할 때 적용 되는 기법이다. Fujii 등 ${ }^{19}$ 은 먼쪽정강종아리관절에 대한 관절가동기 법은 관절 공간을 증가시키고 목말종아리관절에서의 충돌을 감소시 켜 발등쪽굽힘의 끝범위를 개선시켰다고 보고하였다. 그러나, 이러한 연구는 LAS를 갖고 있는 대상자가 아닌 사체를 대상으로 한 연구이 며, 정강종아리관절에 대한 가동기법이나 도수교정에 대한 연구는 거의 없는 실정이다. Moiler 등 ${ }^{28}$ 은 LAS 병력이 있는 농구선수를 대상 으로 먼쪽종아리뼈의 위치 결함을 교정하기 위한 테이핑을 적용해 LAS의 재발에 예방 효과가 있다고 보고하였다. 이러한 연구를 통해 정강종아리관절의 정상화는 LAS의 재발 방지에 도움이 될 것으로 고려된다. 그러나 선행연구들은 주로 먼쪽정강종아리관절에 대한 고 려가 대부분이다. 몸쪽과 먼쪽정강종아리관절은 서로에 대해 독립 적으로 움직이는 것이 아니라 하나의 기능적 단위로 같이 움직인다. 
따라서 본 연구에서는 정강종아리관절에 대한 도수교정을 먼쪽에만 적용한 것이 아니라 몸쪽과 먼쪽을 같이 적용하여 정강뼈에 대한 종 아리뼈의 정상적 관절운동형상학을 회복하려 시도하였다.

체중부하 상태하에서의 발목의 발등쪽굽힘 제한은 균형에 영향 을 미칠 수 있다. ${ }^{16}$ 이러한 발등쪽굽힘의 감소와 균형의 문제는 LAS의 중요한 재발 요인이 된다. 관절의 가동기법과 도수교정은 관절운동형 상학과 가동범위를 증가시키는 역학적 효과만 갖는 것이 아니라, 관 절 주위의 감각수용기를 활성시키는 신경계에 대한 효과도 가질 것 으로 생각된다. Grindstaff 등 29 은 CAI 환자의 먼쪽정강종아리관절에 대한 도수교정을 통해 가자미근의 활성 증가를 확인하였다. 그러나 몸쪽정강종아리관절에 대한 도수교정에서는 근육의 활성을 확인하 지 못했다. 먼쪽정강종아리관절의 도수교정에 의한 가자미근의 증가 된 활성은 발목을 좀더 잡아주는데 효과가 있을 것이며, 이는 균형의 증가를 유발한다고 볼 수 있다. 본 연구에서는 몸쪽과 먼쪽정강종아 리관절에 대한 도수교정을 통해 동적인 균형이 개선되는 것을 확인 하였다. 몸쪽정강종아리관절의 도수교정이 근육활성에는 영향을 미 치지 못했지만, 몸쪽과 먼쪽정강종아리관절의 도수교정을 통해 정 강뼈에 대한 종아리뼈의 관절운동형상학을 증가시켜 동적 균형에 필요한 역학적 효과를 제공했을 것으로 생각된다.

\section{본 연구의 제한점은 도수교정의 적응증인 저가동성을 관절에서} 직접 확인하지 못한 것이다. 본 연구에서는 관절운동의 저가동성으 로 체중부하 런지검사를 통한 발등쪽굽힘의 감소로 제시하였지만, 앞으로의 연구에서는 도수교정을 적용하는 관절에 대해 직접적인 가동성 검사가 필요할 것으로 생각된다.

\section{Acknowledgements}

The Research has been conducted by the Research Grant of Gwangju Health University in 2015(No. 3015008).

\section{참고문헌}

1. Barker HB, Beynnon BD, Renstron PA. Ankle injury risk factors in sports. Sports Med. 1997;23:69-74.

2. Feger MA1, Glaviano NR, Donovan L et al. Current trends in the management of lateral ankle sprain in the United States. Clin J Sport Med. 2017;27(2):145-52.

3. Fallat L, Grimm DJ, Saracco JA. Sprained ankle syndrome: Prevalence and analysis of 639 acute injuries. J Foot Ankle Surg. 1998;37(4):280-5.

4. Hubbard TJ, Wikstrom EA. Ankle sprain: Pathophysiology, predisposing factors, and management strategies. Open Access J Sports Med. 2010; 16:115-22.

5. Czajka CM, Tran E, Cai AN et al. Ankle sprains and instability. Med Clin North Am. 2014;98(2):313-29.
6. van Rijn RM, van Os AG, Bernsen RM et al. What is the clinical course of acute ankle sprains? a systematic literature review. Am J Med. 2008; 121(4):324-31.

7. Martin RL, Davenport TE, Paulseth S et al. Ankle stability and movement coordination impairments: Ankle ligament sprains. J Orthop Sports Phys Ther. 2013;43(9):A1-40.

8. Drewes LK, McKeon PO, Kerrigan DC et al. Dorsiflexion deficit during jogging with chronic ankle instability. J Sci Med Sport. 2009;12(6):685-7.

9. Palmieri-Smith RM, Hopkins JT, Brown TN. Peroneal activation deficits in persons with functional ankle instability. Am J Sports Med. 2009; 37(5):982-8.

10. Halabchi F, Angoorani H, Mirshahi M et al. The prevalence of selected intrinsic risk factors for ankle sprain among elite football and basketball players. Asian J Sports Med. 2016;7(3):e35287.

11. Cruz-Díaz D, Lomas Vega R, Osuna-Pérez MC et al. Effects of joint mobilization on chronic ankle instability: A randomized controlled trial. Disabil Rehabil. 2015;37(7):601-10.

12. Marrón-Gómez D, Rodríguez-Fernández ÁL, Martín-Urrialde JA. The effect of two mobilization techniques on dorsiflexion in people with chronic ankle instability. Phys Ther Sport. 2015;16:10-5.

13. Vicenzino B, Branjerdporn M, Teys P et al. Initial changes in posterior talar glide and dorsiflexion of the ankle after mobilization with movement in individuals with recurrent ankle sprain. J Orthop Sports Phys Ther. 2006;36(7):464-71.

14. Cruz-Díaz D, Lomas Vega R, Osuna-Pérez MC et al. Effects of joint mobilization on chronic ankle instability: A randomized controlled trial. Disabil Rehabil. 2015;37(7):601-10.

15. Hoch MC, Andreatta RD, Mullineaux DR et al. Two-week joint mobilization intervention improves self-reported function, range of motion, and dynamic balance in those with chronic ankle instability. J Orthop Res. 2012;30(11):1798-804.

16. Hoch MC, McKeon PO. Joint mobilization improves spatiotemporal postural control and range of motion in those with chronic ankle instability. J Orthop Res. 2011;29(3):326-32.

17. Fisher BE, Piraino A, Lee YY et al. The effect of velocity of joint mobilization on corticospinal excitability in individuals with a history of ankle sprain. J Orthop Sports Phys Ther. 2016;46(7):562-70.

18. Huber T, Schmoelz W, Bölderl A. Motion of the fibula relative to the tibia and its alterations with syndesmosis screws: a cadaver study. Foot Ankle Surg. 2012;18(3):203-9.

19. Fujii M, Suzuki D, Uchiyama E et al. Does distal tibiofibular joint mobilization decrease limitation of ankle dorsiflexion? Man Ther. 2010; 15(1):117-21.

20. Bennell KL, Talbot RC, Wajswelner H et al. Intra-rater and inter-rater reliability of a weight-bearing lunge measure of ankle dorsiflexion. Aust J Physiother. 1998;44(3):175-80.

21. Beazell JR, Grindstaff TL, Sauer LD et al. Effects of a proximal or distal tibiofibular joint manipulation on ankle range of motion and functional outcomes in individuals with chronic ankle instability. J Orthop Sports Phys Ther. 2012;42(2):125-34

22. Fryer GA, Mudge JM, McLaughlin PA. The effect of talocrural joint manipulation on range of motion at the ankle. J Manipulative Physiol Ther. 2002;25(6):384-90.

23. Harkey M, McLeod M, Van Scoit A et al. The immediate effects of an 
anterior-to-posterior talar mobilization on neural excitability, dorsiflexion range of motion, and dynamic balance in patients with chronic ankle instability. J Sport Rehabil. 2014;23(4):351-9.

24. Andersen S, Fryer GA, McLaughlin P. The effect of talo-crural joint manipulation on range of motion at the ankle joint in subjects with a history of ankle injury. Australas Chiropr Osteopathy. 2003;11(2):57-62.

25. Hubbard TJ, Hertel J. Anterior positional fault of the fibula after subacute lateral ankle sprains. Man Ther. 2008;13(1):63-7.

26. Fukuhara T, Sakamoto M, Nakazawa R et al. Anterior positional fault of the fibula after sub-acute anterior talofibular ligament injury. J Phys Ther Sci. 2012;24:115-7.
27. Kavanagh J. Is there a positional fault at the inferior tibiofibular joint in patients with acute or chronic ankle sprains compared to normals? Man Ther. 1999;4:19-24.

28. Moiler K, Hall T, Robinson K. The role of fibular tape in the prevention of ankle injury in basketball: a pilot study. J Orthop Sports Phys Ther. 2006;36(9):661-8.

29. Grindstaff TL1, Beazell JR, Sauer LD et al. Immediate effects of a tibiofibular joint manipulation on lower extremity H-reflex measurements in individuals with chronic ankle instability. J Electromyogr Kinesiol. 2011;21(4):652-8. 